\title{
Gender differences in university EFL students' language proficiency corresponding to self-rated attention, hyperactivity and impulsivity
}

\section{Hsin-Yi Liang ${ }^{1}$, Brent A. Kelsen ${ }^{2}$}

${ }^{1}$ Department of Child Psychiatry, Chang Gung Memorial Hospital at Linkou \& Chang Gung University, Taoyuan

${ }^{2}$ Language Center, National Taipei University, New Taipei City

\section{Taiwan}

Correspondence: Brent A. Kelsen. Language Center, National Taipei University, 151 Da Xue Rd., SanXia District, New Taipei City. Taiwan. E-mail: brentntpu@gmail.com 


\begin{abstract}
Introduction. This study examines university students' self-reported inattention, hyperactivity and impulsivity, and their relation to performance on a high-stakes English proficiency test while taking gender into consideration.

Method. Inattention, hyperactivity and impulsivity attributes were assessed using the Adult Attention Deficit/Hyperactivity Disorder (ADHD) Self-Reported Scale (ASRS) questionnaire. A total of 229 college students enrolled in sophomore EFL courses completed the Chinese version of the ASRS. A high-stakes English proficiency test required as a graduation prerequisite was used to measure their proficiency in English listening and reading performance.
\end{abstract}

Results. Analysis of variance (ANOVA) results revealed no differences between high and low attention deficit, hyperactivity and impulsivity groups with regard to listening, reading and total scores of the English proficiency test. However, after separating the total sample into high and low attention deficit, hyperactivity and impulsivity groups multiple group comparisons demonstrated significant differences according to gender. High attention deficit, hyperactivity and impulsivity scores were associated with lower listening, reading and total scores for male students.

Discussion and Conclusion. The findings are discussed in relation to relevant research in the field and pedagogical implications are considered.

Key words: Inattention, Hyperactivity, Impulsivity, self-reported ADHD symptoms, ASRS, EFL, English proficiency test 


\section{Resumen}

Introducción. Este estudio examina la desatención, la hiperactividad y la impulsividad autoinformadas de los estudiantes universitarios, y su relación con su desempeño en una prueba de proficiencia en inglés de altas exigencia, teniendo en cuenta el género.

Método. Los atributos de falta de atención, hiperactividad e impulsividad se evaluaron mediante el cuestionario de la Auto-Reported Scale (ASRS) del Trastorno de Déficit de Atención de Adultos / Hiperactividad (ADHD). Un total de 229 estudiantes universitarios matriculados en cursos EFM de segundo año completaron la versión china del ASRS. Se usó una prueba de proficiencia en inglés de alto nivel, como requisito de graduación para medir su habilidad en el rendimiento de lectura y lectura en inglés.

Resultados. Los resultados del análisis de varianza (ANOVA) no revelaron diferencias entre los grupos alto y bajo de déficit de atención, hiperactividad e impulsividad con respecto a la audición, la lectura y las puntuaciones totales de la prueba de proficiencia en inglés. Sin embargo, la separación de la muestra total en alto y bajo déficit de atención, la hiperactividad y la impulsividad grupos de múltiples comparaciones de grupos podría demostrar diferencias significativas entre los géneros. Las puntuaciones de alta déficit de atención, hiperactividad e impulsividad se asociaron con menor audición, lectura y puntuaciones totales para los estudiantes varones.

Discusión y conclusión. Los hallazgos se discuten en relación con la investigación relevante en el campo y se consideran las implicaciones instruccionales.

Palabras clave: Inatención, Hiperactividad, Impulsividad, autoinforme, TDAH, ASRS, EFL, Test en inglés

Recibido: 11.02 .16

Aceptación Inicial: 21.10 .16

Aceptación final: 07.02.17 


\section{Introduction}

Anecdotal evidence suggests that a common refrain among instructors is that their students lack the ability to concentrate for sustained periods, struggle to focus on lesson material, are easily distracted by external stimuli and have difficulty settling down. Inattention, hyperactivity and impulsivity are the behavioral symptoms comprising attention deficit hyperactivity disorder (ADHD). Persons exhibiting ADHD symptoms are likely to have a propensity to lack organization skills, suffer from attention-shifting, get distracted easily, exhibit restlessness, have inferior planning and time management capabilities, and struggle with indecision, punctuality and prioritization. ADHD is commonly believed to negatively affect academic performance (Hartanto, Krafft, Iosif \& Schweitzer, 2015), and research has advanced that language learning difficulties may be significantly associated with ADHD symptoms (Jonsdottir, Bouma, Sergeant \& Scherder, 2005; Seidman, 2006). Moreover, recent ADHD research, both internationally (Simon, Czobor, Bálint, Mészáros \& Bitter, 2009; Valera, Brown \& Biederman, 2010) and in Taiwan (Wang, Chen \& Huang, 2015), has also gathered consensus that gender differences exist. Published reviews and meta-reviews (e.g., Gershon, 2002; Martinussen, Hayden, Hogg-Johnson \& Tannock, 2005; Rucklidge, 2010; Skogli, Teicher, Andersen, Hovik \& Øie, 2013) indicated that while females with ADHD showed lower ratings for ADHD, females rated ADHD were usually diagnosed with inattentive sub-type, and that those females with ADHD displayed greater degrees of intellectual impairment and more internalizing issues (anxiety and depression) than males with ADHD.

During the past couple of decades, many countries have witnessed females catch up with and even surpass males in many aspects of educational achievement including language (Cole, 1997; Gibb, Fergusson \& Horwood, 2008; Peacock \& Ho, 2003). Of particular note, individual differences in foreign language learning research has recognized gender-based differences in factors such as motivation (Dörnyei, 2003), learning strategies (Oxford, 1993; Oxford \&Ehrman, 1995; Peacock \& Ho, 2003) and foreign language classroom anxiety (Park \& French, 2013). A number of other studies have identified the phenomenon of females displaying advantages over their male 
counterparts on various aspects of EFL achievement (eg. Gu, 2002; Fernández Fontecha, 2010).

Following the Ministry of Education's policy to encourage colleges and universities to establish English proficiency graduation thresholds for non-English major students, high-stakes tests have become a part of the tertiary education landscape in Taiwan. This saw the number of institutions setting graduation thresholds climb to close to $90 \%$ in 2012 (Pan, 2013). Furthermore, mirroring the increasing importance of highstakes testing on college students in Taiwan, studies of different aspects of high-stakes testing and a variety of English proficiency tests have been published, including analysis of student study and learning strategies (Sheu, Wang \& Hsu, 2013), listening strategies (Chen, 2005) and reading strategies (Lee, 2015).

The present research investigates self-perceived ratings of inattention, hyperactivity, and impulsivity and their influence on student performance in a high-stakes English proficiency test. To measure these behavioral variables a self-report tool ${ }^{1}$ so far unutilized in EFL research is employed. Through this novel approach, the present study aims to investigate whether or not gender plays a role in university students' self-reported ADHD symptoms and performance on a high-stakes EFL proficiency test.

\section{Literature review}

\section{Attention deficit hyperactivity disorder (ADHD)}

ADHD is a commonly occurring neuro-developmental disorder characterized by inattention, hyperactivity and impulsivity (DSM-IV). Research into the etiology of ADHD is ongoing and no single cohesive theory of the disorder yet exists. Explanations of the language impairments resulting from the cognitive deficits characteristic of ADHD have focused primarily on diminished executive functioning of the brain, particularly

\footnotetext{
${ }^{1}$ This research uses the ASRS, a tool used to screen for ADHD, as a metric to quantify inattention, hyperactivity and impulsivity. It must be pointed out that in this article the authors do not wish to suggest that any of the participants actually have ADHD. In clinical settings, the presence of ADHD would be determined through interviews conducted by trained staff. 52 
with regard to working memory. Working memory (WM) has been postulated as a three component model, of which the central executive, verbal storage and visual storage are constituents (Baddeley\& Hitch, 1974; Jonsdottir et al., 2005). A meta-analysis review conducted by Matinussen et al. (2005) found that several WM components of ADHD children exhibited deficits irrespective of language learning and general intellectual ability comorbidity. However, they acknowledge that limitations in the published research regarding measures of WM, methods, and absence of controlling for confounding factors have led to inconsistent results. Inevitably, numerous authors caution that the results of studies into the cognitive deficits resulting from ADHD are mixed and WM models of cognition have been subject to debate (Baddeley \& Lieberman, 1980; Healy \& McNamara, 1997; Jonsdottir et al., 2005; Matinussen et al., 2005).

The incidence of ADHD has steadily risen in Taiwan in recent years and is currently estimated to affect $7.5 \%$ of children and adolescents (Gau et al., 2007). The onset of ADHD usually begins in childhood and untreated may continue into adolescence and adulthood. Research has indicated that the persistence of ADHD symptoms from childhood into adolescence and adulthood may be as high as 60\% (Biederman, Mick \& Faraone, 2000; Rasmussen \& Gillberg, 2000), and in the United States it is estimated that as many as 5\% of adults may experience adult ADHD (Valera et al., 2010). Furthermore, it is generally agreed that ADHD symptoms are manifest at higher rates in males than females (Gau et al., 2007; Polancysk, de Lima, Horta, Biederman \& Rohde, 2007; Simon et al., 2009; Valera et al., 2010).

\section{Learning disorder, ADHD and language learning}

The association between ADHD and related comorbidities such as learning disorders and language impairment has been well documented in learning disability and psychiatric literature (Javorsky, 1996; Jonsdottir et al., 2005; Seidman, 2006). Among children with language impairments, the most common psychiatric diagnosis is ADHD; and at the same time, children with ADHD exhibit language impairment as a common comorbidity. Javorsky (1996) determined that adolescents with language learning disorders and ADHD generally performed less adequately on a battery of language 
evaluations than those with only ADHD or neither language disorder nor ADHD. However, those participants with only language learning disorders didn't score significantly differently from the "ADHD” or "Neither" groups.

Foreign language learning requirements are considered to be especially challenging for tertiary-level students categorized as experiencing learning disabilities as such disabilities are thought to hinder language learning and inhibit foreign language acquisition (Ganschow, Sparks \& Schneider, 1995; Sparks, Javorsky \& Philips, 2004 \& 2005). Nevertheless, a series of studies conducted in the United States using both petition (i.e. receiving accommodations) and non-petition college students classified as learning disabled pointed to the absence of variance among those students regarding numerous measures of academic performance including foreign language performance (Sparks \& Javorsky, 1999; Sparks, Philips, Ganschow \& Javorsky, 1999; Sparks, Philips \& Javorsky, 2002).

Extending this line of deliberation, Sparks et al. (2004 \& 2005) pointed out that students specifically diagnosed with ADHD both with and without learning disability may display learning impediments and academic difficulties. Motivated by a lack of empirical research in this area, they conducted detailed investigations of such college students in the United States and revealed that they were not necessarily disadvantaged regarding academic achievement in general and foreign language achievement in particular (Sparks et al., $2004 \&$ 2005). They concluded that despite their disability classification, students classified as ADHD ought to be encouraged to enroll in foreign language courses as they do not experience difficulties fulfilling such requirements (Sparks et al., 2004). Furthermore, in an outcome they concede may appear somewhat counter intuitive, they discovered that students diagnosed specifically with ADHD might in fact perform better on the foreign language requirement (Sparks et al., 2005).

\section{Conceptualization and research questions}

\section{Theoretical conceptualization}


Individual differences have a long history in EFL literature and gender differences in factors such as motivation (Dörnyei, 2003), learning strategies (Oxford, 1993; Oxford \& Ehrman, 1995; Peacock \& Ho, 2003) and foreign language classroom anxiety (Park \& French, 2013) have been identified. Moreover, a body of literature supports the influence of gender in foreign language learning. In a study conducted on college students in Hong Kong, Boyle (1987) reported that females outperformed males in overall English language proficiency; however, males were found to have an advantage when it came to listening vocabulary. Yet, in another study, Gu (2002) reports on females possessing an advantage with regards to vocabulary size and in general English proficiency. Additionally, Fernández Fontecha (2010) points to a connection between girls' higher levels of intrinsic motivation and lexical availability, while Andreou, Vlachos and Andreou (2005) reveal female superiority regarding semantic and syntactic proficiency.

Meanwhile, researchers in the field of psychiatry have identified ADHD as one risk factor tempering academic achievement (Hartanto, Krafft, Iosif \& Schweitzer, 2015). ADHD symptoms are often found to be comorbid with affective disorders such as anxiety and depression and present along with language and learning disorders (Javorsky, 1996; Jonsdottir et al., 2005; Schatz \& Rostain, 2006; Seidman, 2006). Both epidemiological and clinical studies have found males exhibit ADHD symptoms more commonly than females and are more likely to be affected in terms of severity and psychiatric comorbidity (Biederman et al., 2002; Diamantopoulou, Henricsson \& Rydell, 2005). Furthermore, the gender appropriateness hypothesis (Kerr, Lambert, Stattin \& Klackenberg-Larsson, 1994) asserts that culturally defined behavioral stereotypes for males and females determine how the different sexes are expected to behave (Diamantopoulou et al., 2005). Such stereotyping may represent one of the reasons lower rates of ADHD diagnosis have been evidenced in females. Consequently, gender stereotyping effects might be expected for self-reported ADHD measures which are likely to be prone to reflect the learners' self-beliefs. These self-beliefs, in turn, may be reflected in gendered socialization effects.

Considering such extensive circumstantial evidence, this study combines these notional themes and postulates that gender plays a possible moderating effect in the 
relationship between self-rated ADHD symptoms and EFL performance. Consequently, this research proposes to examine a conceptual framework presented in Figure 1.

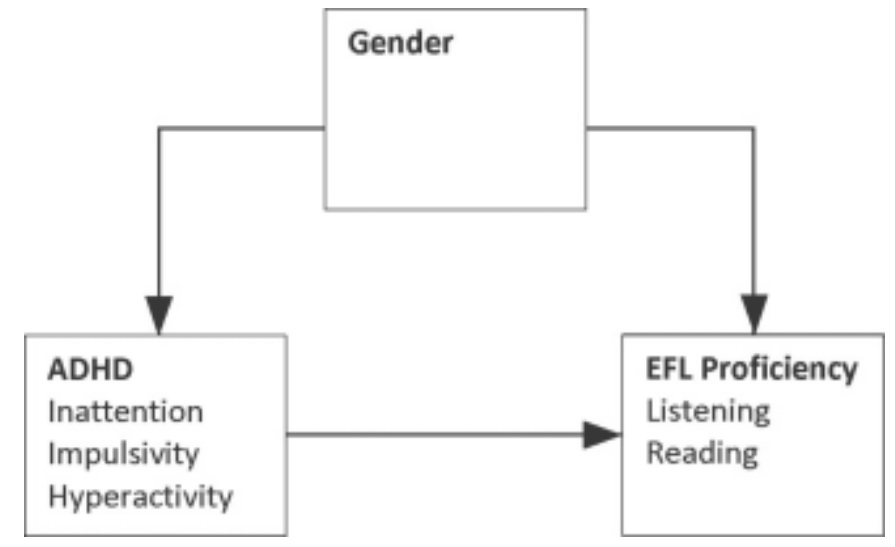

Figure 1. Conceptual model of gender as a moderator

\section{Research questions}

Although the associations among students with ADHD and cognitive deficits and language impairment have been comprehensively documented, published research regarding attention deficit, hyperactivity and impulsivity and EFL acquisition is scarce, not to mention a lack of studies incorporating a gender perspective. This study proposes to incorporate the gender perspective revealed in recent research and examine a group of college students with respect to their inattention, hyperactivity and impulsivity, as measured by the Adult ADHD Self-Report Scale (ASRS), and their performance on a high-stakes EFL test. Accordingly, three key research questions are addressed:

1) Do self-reported attention deficit, hyperactivity and impulsivity symptoms affect EFL test scores?

2) Is there a gender difference in self-reported attention deficit, hyperactivity and impulsivity symptoms and EFL test performance?

3) Do the self-reported attention deficit, hyperactivity and impulsivity symptoms affect listening, reading and overall scores differently?

\section{Methods}

\section{Participants}


The participants in this study were students at a university in northern Taiwan, enrolled in Sophomore English for non-English major classes. All students participated in the survey voluntarily and consented to their English test scores being matched with their ASRS ratings. As far as the authors were aware, none of the students were seeking accommodations for learning disorders. The average age of the 229 participants was 20.66 years (male: $M=21.01, S D=1.6$; female: $M=20.44, S D=0.65)$, while 89 (38.9\%) were male and $140(61.1 \%)$ were female. All students were Mandarin speakers.

Sophomore English for non-English major students are placed into three levels based on results of a placement test conducted in their freshman year. For this sample, the students came from Level A (high level; $n=73 ; 31.9 \%$ ), Level B (middle level; $n=67$; 29.3\%), and Level C (low level; $n=89 ; 38.9 \%$ ). Broken down by major, the students sampled could be categorized as belonging to the following: business $(n=49,21.4 \%)$; languages $(n=72,31.4 \%)$; social sciences $(n=71,31 \%)$; sciences $(n=37,16.2 \%)$.

\section{Measures}

\section{Adult ADHD Self-Report Scale (ASRS)}

The ASRS is an instrument which was developed by Harvard Medical School in conjunction with the World Health Organization and consists of 18 questions. Items on the ASRS are consistent with the criteria established for adult ADHD set out in the Diagnostic and Statistical Manual of Mental Disorders, Fourth Edition (DSM-IV) (Kessler et al., 2005; Gau et al., 2007). Internal consistency, measured by Chronbach's alpha, of the Chinese version of the ASRS for the inattention and hyperactivityimpulsivity subscales have demonstrated good results, as have test-retest properties and construct validity (Gau et al., 2007; Yeh, Gau, Kessler \& Wu, 2008). For the present study, Cronbach's alpha for the inattention subscale was 0.7 and that for the impulsivity and hyperactivity subscale was 0.81 , indicating that both displayed sufficient internal consistency.

Section A of the ASRS is composed of 9 items measuring inattention, while section B comprises 9 items assessing hyperactivity and impulsivity. Occurrence of 
symptoms over the past 6 months is assessed via a 5-point Likert scale: $0=$ never, $1=$ rarely, $2=$ sometimes, $3=$ often, and 4=very often (Kessler et al., 2005). This research follows the method and classification described in Gau et al. (2007), although with slightly different labels. Scores of 0 to 16,17 to 23, and 24 and over on either of the subscales denote that the individual is considered unlikely to have ADHD (unlikely $A D H D$ ), likely to have ADHD (probable ADHD), and highly likely to have ADHD (very likely $A D H D$ ). Following this, the scores from both the inattention and hyperactivity and impulsivity subscales were combined to give highly likely $A D H D$ (very likely $A D H D$ on both subscales), probably $A D H D$ (probable $A D H D$ on both subscales), and possibly $A D H D$ (probable $A D H D$ on either subscale). Those who did not register in these categories were placed in the unlikely $A D H D$ group.

\section{Soochow University English Proficiency Test (SCUEPT)}

The Soochow University English Proficiency Test (SCUEPT) is an English proficiency test based on the high-intermediate level of the General English Proficiency Test (GEPT) in Taiwan. Research has shown the construct validity and internal consistency of the SCUEPT to be satisfactory (Gong, 2004 \& 2007). English for nonEnglish major students at Soochow University are required to pass the SCUEPT during their sophomore year. However, students who have achieved comparable or higher standards on stand-alone English proficiency tests may apply to be exempt from this requirement. Accordingly, a number of students do not sit the SCUEPT for this reason.

The SCUEPT takes 100 minutes and consists of 85 multiple choice answers (a, b, c or d) for a total of 85 points. It is divided into two sections - listening and reading worth 40 and 45 points, respectively. The Listening Comprehension section consists of two parts: Part A (25 questions) covers short dialogs and Part B (15 questions) consists of longer passages. The Reading section is comprised of two parts: Part 1 (25 questions) has sentence completions and Part 2 (20 points) includes short skimming and longer passages. Raw scores were aggregated into overall listening Listen, overall reading Read and total score Total for use in this analysis. The correlation between Listen and Read was $0.537(\mathrm{p}<0.01)$, showing a moderate degree of association. 


\section{Procedure}

Sampling of the target population took place in weeks fifteen and sixteen of the spring semester (late May/early June). Clearance to undertake this research project was received from the Language Center before data collection began. Teachers from eight ( 2 Level A, 3 Level B and 3 Level C) classes of Sophomore English distributed 295 ASRS questionnaires. Of the returned questionnaires, 21 were discarded due to incompleteness, and 45 did not have matching SCUEPT scores. Therefore, 229 (77.6\%) of the questionnaires were correctly completed, returned, and later matched with corresponding SCUEPT scores.

\section{Data analysis}

For the purpose of performing analysis of variance (ANOVA), this study divided the participants into two groups according to their ADHD symptom classification: likely $A D H D$ (comprised of highly likely $A D H D$ and probably ADHD groups) and unlikely $A D H D$ (comprised of possibly $A D H D$ and unlikely $A D H D$ groups). This both simplified the analysis and ensured that the groups consisted of large enough absolute counts for computational purposes. Of the 229 participants, 42 (male $=21$, female $=21$ ) were in the likely $A D H D$ group and 187 (male=68, female=119) were in the unlikely ADHD group.

Visual inspection of Q-Q plots for the dependent variable Listen, Read and Total showed they were approximately normally distributed. A number of tests to investigate the distribution parameters of the dependent variables were performed and supported the assumption of normality. ${ }^{2}$ The statistics were as follows: skewness (0.093, $\left.S E=0.255\right)$, kurtosis $(-0.504, S E=0.506)$, and Shapiro-Wilk test $(0.989, d f=89, p=0.665)$ for males and skewness $(-0.357, S E=0.205)$, kurtosis $(0.316, S E=0.407)$, and Shapiro-Wilk test $(0.984$, $d f=140, p=0.105)$ for females. Further Levene's tests were conducted showing (0.244, $d f=87, p=0.623)$ for males and $(0.22, d f=138, p=0.882)$ for females; therefore, verifying the homogeneity of variances. As a result, parametric ANOVAs were used to examine the data.

\footnotetext{
${ }^{2}$ As the statistics were similar for each dependent variable, only those for Total are written here. 


\section{Results}

Means and standard deviations of each of the 18 ASRS items for the overall data set, males and females, are presented in Table 1. The first nine items represent those measuring inattention, and the second nine represent those measuring hyperactivity and impulsivity. The top three highest mean scores were registered for items in the inattention portion of the questionnaire. This result held across both gender groups. Apart from item 11 ( $p=0.035$ ), there were no significant differences between the scoring of the items for males and females.

Table 1. Overall, male and female means and standard deviations for ASRS items

\begin{tabular}{ccccccc}
\hline Item & \multicolumn{2}{c}{$\begin{array}{c}\text { Overall } \\
(N=229)\end{array}$} & \multicolumn{2}{c}{$\begin{array}{c}\text { Male } \\
(n=89)\end{array}$} & & \multicolumn{2}{c}{$\begin{array}{c}\text { Female } \\
(n=140)\end{array}$} \\
& $M$ & $S D$ & $M$ & $S D$ & $M$ & $S D$ \\
\hline 1 & 1.95 & 0.74 & 1.96 & 0.75 & 1.95 & 0.73 \\
2 & 2.10 & 0.84 & 2.16 & 0.84 & 2.06 & 0.84 \\
3 & 1.48 & 0.87 & 1.53 & 0.97 & 1.46 & 0.81 \\
4 & 1.78 & 0.85 & 1.74 & 0.87 & 1.81 & 0.84 \\
5 & 1.77 & 0.86 & 1.83 & 0.96 & 1.74 & 0.80 \\
6 & 2.11 & 0.86 & 2.12 & 0.93 & 2.10 & 0.82 \\
7 & 1.92 & 1.07 & 1.82 & 1.05 & 1.98 & 1.08 \\
8 & 2.32 & 0.83 & 2.30 & 0.82 & 2.33 & 0.83 \\
9 & 1.69 & 0.94 & 1.70 & 0.97 & 1.69 & 0.93 \\
10 & 1.86 & 0.98 & 1.94 & 0.95 & 1.81 & 1.00 \\
11 & 1.12 & 0.87 & 1.27 & 0.94 & 1.02 & 0.81 \\
12 & 1.70 & 0.91 & 1.69 & 0.94 & 1.71 & 0.90 \\
13 & 1.18 & 0.89 & 1.24 & 1.01 & 1.15 & 0.79 \\
14 & 1.31 & 0.87 & 1.27 & 0.90 & 1.34 & 0.85 \\
15 & 1.45 & 0.93 & 1.44 & 0.94 & 1.46 & 0.92 \\
16 & 1.44 & 0.84 & 1.43 & 0.94 & 1.45 & 0.77 \\
17 & 1.29 & 0.97 & 1.33 & 1.13 & 1.26 & 0.86 \\
18 & 1.22 & 0.69 & 1.27 & 0.73 & 1.19 & 0.66 \\
\hline
\end{tabular}

The results in Table 2 show the test score means and standard deviations for the two groups unlikely $A D H D$ and likely $A D H D$ along with the $F$ test statistics and $p$-values for differences between the two groups. One-way ANOVA showed there were no significant differences between the unlikely $A D H D$ and likely $A D H D$ groups with regard to any measure of students' test scores. For those students who were unlikely ADHD, the 60 - 
means and standard deviations for Listen, Read, and Total test scores were $M=23.63$, $S D=5.9, M=23.57, S D=5.67$, and $M=47.19, S D=10.29$; while those for students placed in the likely $A D H D$ group were $M=22.64, S D=6.63, M=22.52, S D=6.21$, and $M=45.17$, $S D=11.90$. Consequently, from this overall perspective, there were no discernable differences between the groups (Figure 2).

Table 2. ANOVA: overall group differences

\begin{tabular}{lccccccc}
\hline & $\begin{array}{c}\text { unlikely ADHD } \\
(n=187)\end{array}$ & \multicolumn{2}{c}{$\begin{array}{c}\text { likely ADHD } \\
(n=42)\end{array}$} & \multicolumn{3}{c}{ Group differences } \\
& $M$ & $S D$ & $M$ & $S D$ & $d f$ & $F$ & $p$ \\
\hline Listen & 23.63 & 5.90 & 22.64 & 6.63 & 1,228 & 0.909 & 0.341 \\
Read & 23.57 & 5.67 & 22.52 & 6.21 & 1,228 & 1.12 & 0.291 \\
Total & 47.19 & 10.29 & 45.17 & 11.90 & 1,228 & 1.254 & 0.264 \\
\hline
\end{tabular}

Note. One-way ANOVA here is equivalent to performing a $t$-test

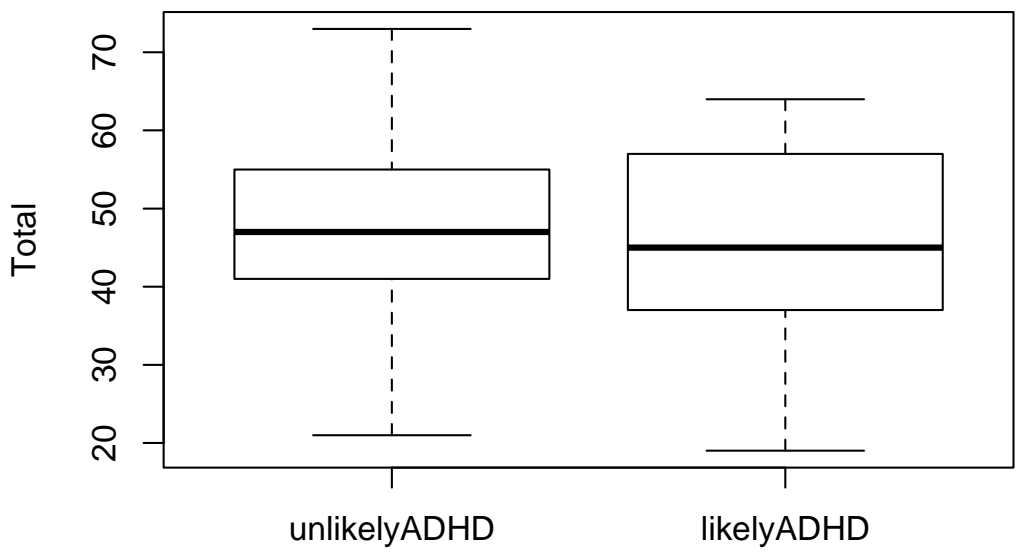

ADHD

Figure 2. Boxplot: Total score: unlikely ADHD \& likely ADHD

Results obtained after dividing the participants based on gender are displayed in Table 3. The data were analyzed using a two-way ANOVA, and the $F$-statistics and $p$ - 
values indicate whether differences existed between the groups. For this sample, differences were observed between the groups that were significant at the $\alpha=0.01$ level. Since statistically significant differences existed, post hoc Scheffé tests were conducted to ascertain which individual group means were significantly different. The Scheffé test is considered a conservative test for comparing individual group means and was therefore selected for this study as being appropriate to control for Type I errors (Winer, Brown and Michels, 1991; Javorsky, 1996). The Scheffé tests indicate that unlikely ADHD and likely $A D H D$ females scored higher on the test than did likely $A D H D$ males. In addition, to control for family-wise Type I errors when conducting multiple comparisons, the Holm's sequential Bonferonni method (Abdi, 2010; Holm, 1997) was applied to the estimated $p$-values at the $\alpha=0.05$ significance level. All results were deemed to hold as reported using the post hoc Scheffé tests.

Effect size statistics were calculated using Cohen's $d$ for those comparisons of means where significant differences were found. For likely ADHD females compared to likely ADHD males they were: Listen $(d=0.45)$, Read $(d=0.52)$ and Total $(d=0.52)$, indicating moderate effect sizes. For unlikely $A D H D$ females and likely $A D H D$ males they were: Listen $(d=0.37)$, Read $(d=0.4)$ and Total $(d=0.42)$, indicating low to moderate effect sizes (Cohen, 1988). Variation between the groups is displayed in Figure 3 where differences between the group means can clearly be seen.

Table 3. ANOVA: male-female/unlikely-likely ADHD group differences

\begin{tabular}{|c|c|c|c|c|c|c|c|c|c|c|c|c|c|}
\hline & \multicolumn{4}{|c|}{ Male } & \multicolumn{4}{|c|}{ Female } & \multicolumn{4}{|c|}{ Group differences } & \\
\hline & \multicolumn{2}{|c|}{$\begin{array}{c}\text { unlikely } A D H D \\
\text { (group } 1, n=68 \text { ) }\end{array}$} & \multicolumn{2}{|c|}{$\begin{array}{l}\text { likely } A D H D \\
\text { (group } 2, n=21 \text { ) }\end{array}$} & \multicolumn{2}{|c|}{$\begin{array}{l}\text { unlikely } A D H D \\
\text { (group } 3, n=119 \text { ) }\end{array}$} & \multicolumn{2}{|c|}{$\begin{array}{l}\text { likely } A D H D \\
\text { (group } 4, n=21 \text { ) }\end{array}$} & & & & & \\
\hline & $M$ & $S D$ & $M$ & $S D$ & $M$ & $S D$ & $M$ & $S D$ & $\overline{D f}$ & $F$ & $p$ & Scheffé & $\eta^{2}$ \\
\hline Listen & 22.49 & 6.32 & 19.19 & 6.18 & 24.28 & 5.57 & 26.10 & 5.18 & 3,225 & 6.61 & 0.0001 & $2<3,4$ & 0.081 \\
\hline Read & 22.79 & 6.06 & 19.71 & 5.49 & 24.01 & 5.41 & 25.33 & 5.70 & 3,225 & 4.53 & 0.004 & $2<3,4$ & 0.057 \\
\hline Total & 45.28 & 11.22 & 38.90 & 10.68 & 48.29 & 9.59 & 51.43 & 9.68 & 3,225 & 6.97 & 0.0001 & $2<3,4$ & 0.085 \\
\hline
\end{tabular}

Note. Post hoc test for differences between groups is Scheffé test. 


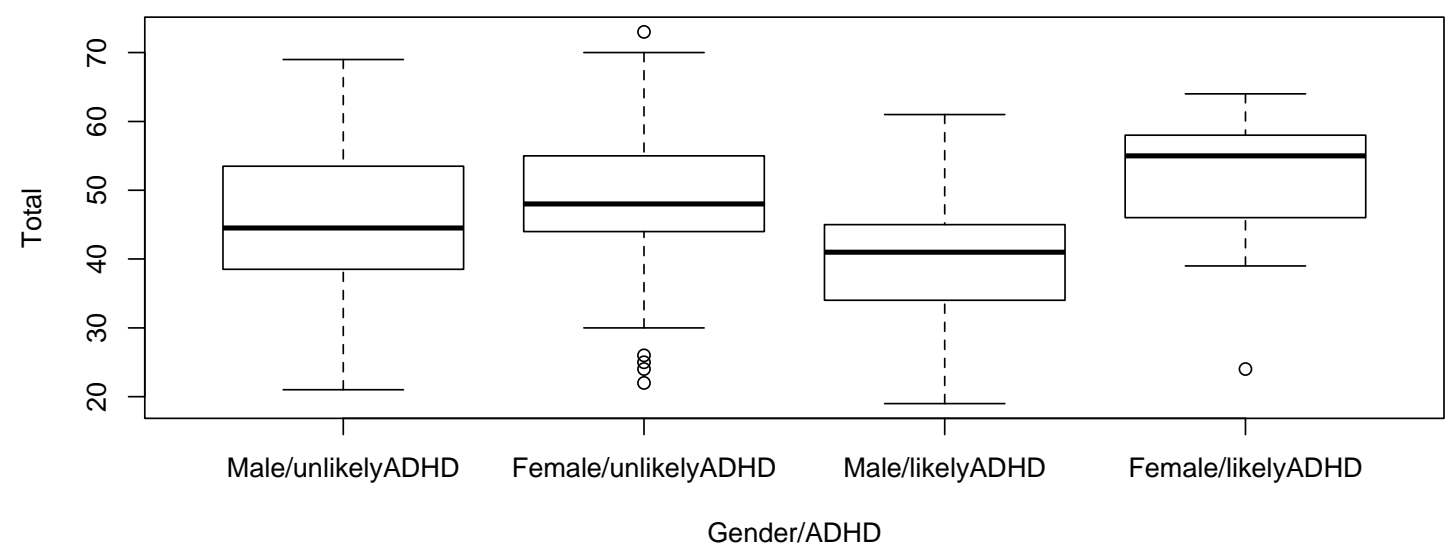

Figure 3. Boxplot: Total score: Gender/unlikely ADHD and likely ADHD

Table 4 presents two-way ANOVA statistics including an ADHD*gender interaction term. It reveals significant main effects for gender and for the interaction for each section of the test. Figures 4 graphically display the ADHD*gender interaction effect plots for listening, reading and total scores. There is an obvious crossover interaction indicating that females in the likely $A D H D$ group attained higher scores on all aspects of the exam, while males in the likely $A D H D$ group performed worst. Females and males in the unlikely $A D H D$ groups occupied the middle ground.

Table 4. ANOVA with main effects and interactions

\begin{tabular}{llccccc}
\hline \multirow{4}{*}{ Listen } & Variable & $M S$ & $d f$ & $F$ & $p$ & ${\text { Partial } \eta^{2}}^{\circ}$ \\
& gender & 639.09 & 1 & 18.84 & 0.001 & 0.077 \\
& adhd & 18.43 & 1 & 0.54 & 0.462 & 0.002 \\
& gender*adhd & 220.88 & 1 & 6.51 & 0.011 & 0.028 \\
& error & 33.93 & 225 & & & \\
& gender & 394.55 & 1 & 12.39 & 0.001 & 0.052 \\
& adhd & 26.02 & 1 & 0.817 & 0.367 & 0.004 \\
& gender*adhd & 163.94 & 1 & 5.148 & 0.024 & 0.022 \\
& error & 31.85 & 225 & & & \\
& gender & 2037.94 & 1 & 19.563 & 0.001 & 0.08 \\
& adhd & 88.25 & 1 & 0.847 & 0.358 & 0.004 \\
& gender*adhd & 765.4 & 1 & 7.347 & 0.007 & 0.032 \\
\hline
\end{tabular}




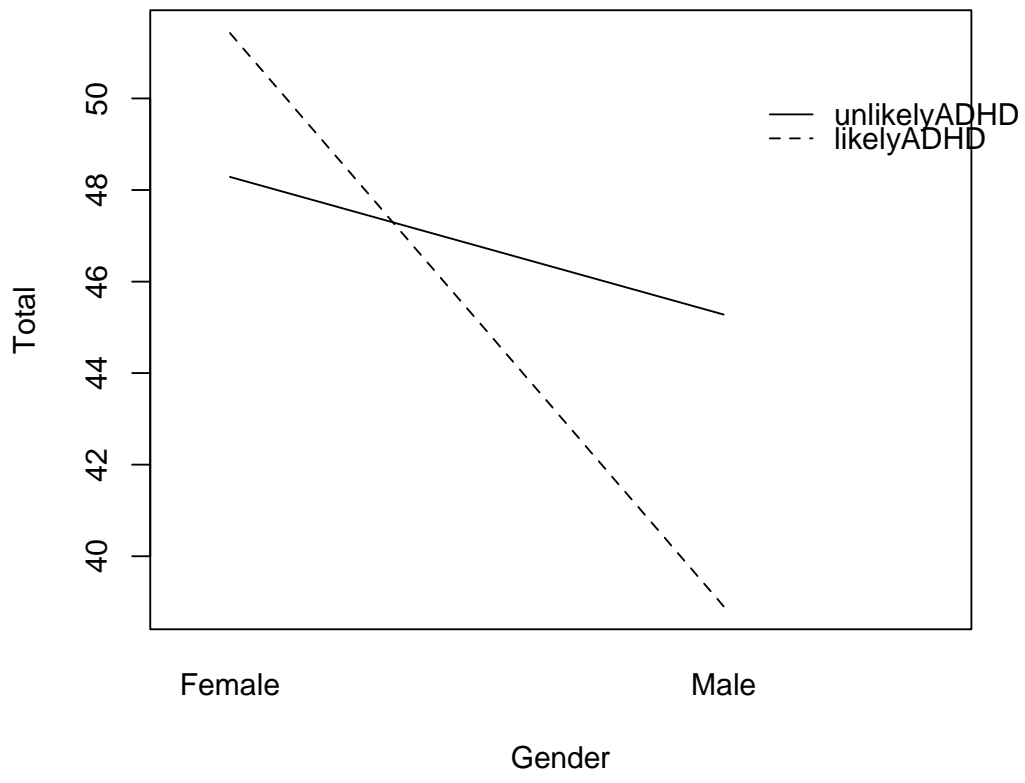

Figure 4. Interaction plot: Total score: unlikely $A D H D$ and likely $A D H D$

\section{Discussion}

In response to the first research question, the findings of the present study could not demonstrate any significant differences between students classified as unlikely $A D H D$ and likely $A D H D$ for either listening, reading or total test scores. This result was consistent with those reported in earlier studies (e.g. Javorsky, 1996 \& 1999; Sparks et al., $2004 \& 2005$ ) and would appear to support the contention that ADHD alone does not significantly account for poorer results when learning foreign languages.

With respect to the second research question, once the students were divided into male and female groups, variation became apparent. As recent research (e.g. Simon et al., 2009; Valera et al., 2010; Wang et al., 2015) would predict, a larger percentage of male students were screened as possibly exhibiting self-reported ADHD symptoms (22\%) compared to females (14\%). Following this division, analysis found that group differences existed. A series of ANOVA procedures established that: (i) likely ADHD 
males performed worse on the measures of the English proficiency test than both likely and unlikely $A D H D$ females, though there were no significant differences with unlikely $A D H D$ males; (ii) unlikely $A D H D$ males did not perform significantly differently from likely $A D H D$ males, nor did they perform significantly differently from likely or unlikely $A D H D$ females; (iii) likely $A D H D$ females performed significantly better than likely $A D H D$ males, yet they didn't perform significantly differently from the unlikely $A D H D$ female group even though their scores were higher for every section; and (iv) unlikely $A D H D$ females also performed significantly better than likely $A D H D$ males with regard to all aspects of the test scores.

ANOVA results including a gender*ADHD interaction provide significant interaction terms at the $\alpha=0.05$ level for the listening and reading scores and at the $\alpha=0.01$ level for the total test score, with clear crossover interactions displayed. Consequently, this analysis suggests that ADHD symptoms potentially have an association with lower test performance in males but not females. This corresponds with more recent inquiries in the field of ADHD research (Simon et al., 2009; Valera et al., 2010; Wang et al., 2015) and indicates the potential existence of a moderating gender effect insufficiently researched in previous studies examining the effect of ADHD symptoms on EFL performance. Although the results reported were statistically significant, the authors acknowledge that the effect sizes were low to moderate and that the eta and partial eta values calculated account for relative little variance by each of the main and interaction effects.

In regard to the third research question, similar patterns were generally displayed across listening, reading and total test scores, suggesting that the impact of gender and self-perceived ADHD symptoms were not expressed differently according to the different language skills required. However, speaking and writing skills, which may require a greater cognitive load, were not included in the high-stakes test employed in this study and thus not considered during this research. 


\section{Implications}

The present study identifies gender as a possible moderating variable influencing the impact of self-reported ADHD symptoms on performance in an English proficiency test. This moderating effect was postulated in the theoretical conceptualization of this study. Gender differences in learning strategies have been identified in numerous studies, with females generally using more social/affective strategies and males more memorization strategies (Hong-Nam \& Leavell, 2006; Oxford, 1993). This research indicates the need for instructors to consider a range of factors affecting students, especially those males who may suffer from inattention, hyperactivity and impulsivity, and offer a broad range of language learning strategies that best suit their individual learning styles.

Further, the results of the present study concur with previous research finding female achievement in EFL surpasses that of males (Glowka, 2014). Their result is attributed as confirmation of socio-linguistic theories of language learning which assert that females are more open to new linguistic forms in the target language and more readily exclude incorrect forms in their interlanguage (Ellis, 2012; Glowka, 2014). Further, the results of this investigation offer further support for Glowka's contention that educational systems in general, and the standard varieties of language preferred for tests in particular, favor females' learning behaviors. Somewhat similar results were discovered by $\mathrm{Gu}$ (2002) who reported sex-based differences in both general EFL performance and vocabulary learning strategies favored females.

For instructors who may encounter challenges and issues relating to inattention, hyperactivity and impulsivity, a number of specific test-taking strategies are available to help students prepare for success in high-stakes testing situations. With regard to listening strategies, several approaches to improving listening skills, such as: awareness and consciousness raising strategies, appropriate materials selection, and expanding learner background knowledge for listening comprehension, among others, may be employed to overcome the numerous barriers to developing effective listening strategies (Chen, 2005). Regarding reading strategies, including top-down as well as bottom-up 
strategies in curricula to account for the cultural and linguistic differences of Chinese speakers, along with the use of multiple-choice test management strategies to guide students to the key points and supplementary aspects of the text are worthy of consideration (Lee, 2015). Indeed, considering that many of the aforementioned approaches are already employed to varying degrees in EFL classrooms likely mitigates the extent to which the constructs under study potentially impact learning outcomes.

\section{Limitations}

Although this research contributes to broaden the perspective of students' selfreported inattention, hyperactivity and impulsivity with respect to a high-stakes test in an EFL setting, there are a number of limitations that need to be acknowledged when interpreting the results. The data collected does not include information on any aspects of learning deficiencies or English language assessment other than ADHD symptoms as measured by the ASRS and English proficiency as examined by the SCUEPT. As none of the students were known to have sought accommodations for learning disorders, this avenue was not further explored. However, this fact may point to a potential motivational and/or gender bias resulting from the self-reported nature of this questionnaire. To further investigate this line of inquiry, additional measures of inattention, hyperactivity and impulsivity, such as those reported by instructors, could pose one direction of future research.

Furthermore, as English language performance only as examined by the SCUEPT was considered, oral and written skills were overlooked, as were other measures of learning and intelligence which may give an indication of the educational potential of participants. Additionally, it is important to note that the ASRS is used as a screening tool and, in clinical settings, is followed by an interview with a mental health professional to establish whether the disorder is actually present. It must also be conceded that due to the moderate sample size, the number of participants allocated to the likely ADHD groups was somewhat constrained and reduces the reliability of the results. Future research would do well to surmount this difficulty by recruiting participants on a larger scale. Moreover, further research efforts should incorporate longitudinal designs to analyze the 
relations among $\mathrm{ADHD}$, EFL proficiency, and gender, with particular reference to the direction of the effects. However, including participants from numerous majors and departments, as this study does, aids the generalizabilty of the results with regard to regular university student populations.

\section{Conclusion}

This research gives another view of the influence of self-reported inattention, hyperactivity and impulsivity on language learning, specifically learning English as a foreign language. Based on the initial findings, this study agrees with formerly published articles in that there were no overall significant differences to be found regarding ADHD symptoms and language performance (Javorsky, 1996 \& 1999; Sparks et al., 2004 \& 2005). However, this investigation revealed that once the data were analyzed from the perspective of gender there were statistically significant differences between certain groups of students. That is, in general, male students who were likely ADHD had English language performance below females who were both likely $A D H D$ and unlikely ADHD. Here, it must be noted that this research differs from many of the previous studies in that it is conducted in a normal student population rather than students selected due to their having a learning disorder, language learning disorder, or clinically diagnosed ADHD.

Finally, by demonstrating students' gender as a potential significant risk factor possibly impeding their EFL learning, this analysis sheds additional light on the influence of inattention, hyperactivity and impulsivity on high-stakes EFL test performance and raises educators' awareness of those groups of students who may be particularly vulnerable. By doing so, the authors attempt to take a small step in the direction of elucidating one little-researched aspect of potential high-stakes EFL test underachievement. It is also hoped that this study may encourage researchers to further investigate this important subject. Undoubtedly, future research into the grounds for the gender-based differences uncovered in this research is warranted. 


\section{References}

Abdi, H. (2010). Holm's sequential Bonferroni procedure. In N. Salkind (Ed.), Encyclopedia of Research Design (pp. 574 -578). Thousand Oaks, CA: Sage Publications.

American Psychiatric Association. (2000). Diagnostic and Statistical Manual of Mental Disorders (Fourth Edition, Text Revision) DSM-IV. Washington, D.C. doi:10.1176/appi.books.9780890423349

Andreou, G., Vlachos, F. \& Andreou, E. (2005). Affecting factors in second language learning. Journal of Psychololinguistic Research, 34(5), 429-438. doi:10.1007/s10936-005-6202-0

Baddeley, A., Hitch, G.J. (1974). Working memory. In G.A. Bower (Ed.), Recent advances in learning and motivation (pp. 47-90). New York: Academic Press. doi:http://dx.doi.org/10.1016/S0079-7421(08)60452-1

Biederman, J., Mick, E., Faraone, S.V. (2000). Age-dependent decline of symptoms of of attention deficit hyperactivity disorder: Impact of remission definition and symptom type. American Journal of Psychiatry, 157(5), 816-818. doi:10.1176/appi.ajp.157.5.816

Biederman, J., Mick, E., Faraone, S. V., Braaten, E., Doyle, A., Spencer, T., Wilens, T., Frazier, E., \& Johnson, M. A. (2002). Influence of gender on attention deficit hyperactivity disorder in children referred to a psychiatric clinic. American Journal of Psychiatry, 159(1), 36-42. doi:10.1176/appi.ajp.159.1.36

Boyle, J. P. (1987). Sex differences in listening vocabulary. Language Learning, 37(2), 273-284. doi:10.1111/j.1467-1770.1987.tb00568.x

Chen, Y. (2005). Barriers to acquiring listening strategies for EFL learners and their pedagogical implications. TESL-EJ, 8(4), 1-22.

Cohen, J. (1988). Statistical power analysis for the behavioral sciences (2nd ed.). Hillsdale, NJ: Lawrence Erlbaum Associates.

Cole, N.S. (1997). The ETS gender study: how females and males perform in educational setting. Princeton, NJ: Educational Testing Service. 
Cumyn, L., French, L., \& Hechtman, L. (2009). ADHD and comorbid depression. Current Attention Disorders Reports, 1(2), 53-59. doi:10.1007/s 12618-009-0008-1

Diamantopoulou, S., Henricsson, L., \& Rydell, A. M. (2005). ADHD symptoms and peer relations of children in a community sample: examining associated problems, self-perceptions, and gender differences. International Journal of Behavioral Development, 29(5), 388-398. doi: https://doi.org/10.1177/01650250500172756

Dörnyei, Z. (2003). Attitudes, orientations, and motivations in language learning: advances in theory, research, and applications. Language Learning, 53(1), 3-32. doi: $10.1111 / 1467-9922.53222$

DuPaul, G.J., Schaughency, E.A., Weyandt, L.L., Tripp, G., Kiesner, J., Ota, K., Stanish, H. (2001). Self-report of ADHD symptoms in university students: Cross-gender and cross-national prevalence. Journal of Learning Disabilities, 34(4), 370-379.

Ellis, R. (2012). The study of second language acquisition (2nd ed.). Oxford: Oxford University Press.

Fernández Fontecha, A. (2010). Gender and motivation in EFL vocabulary production. In R.M.J. Catalán (Ed.), Gender perspectives on vocabulary in foreign and second languages (pp. 93-116). Basingstoke: Palgrave Macmillan.

Ganschow, L., Sparks, R., Schneider, E. (1995). Learning a foreign language: Challenges for students with language learning difficulties. Dyslexia, 1(2), 75-95.

Gau, S.S., Kessler, R.C., Tseng, W.L., Wu, Y.Y., Chiu, Y.N., Yeh, C.B, Hwu, H.G. (2007). Association between sleep problems of attention deficit/hyperactivity disorder in young adults. SLEEP, 30(2), 195-201.

Gau, S.S., Shang C.Y. (2010). Improvement of executive functions in boys with attention deficit hyperactivity disorder: an open-label follow-up study with oncedaily atomoxetine. International Journal of Neuropsychopharmacology, 13(2), 243-56. doi: https://doi.org/10.1017/S1461145709990836

Gershon, J. (2002). A meta-analytic review of gender differences in ADHD. Journal of Attention Disorders, 5(3), 143-154. doi: https://doi.org/10.1177/108705470200500302

Gibb, S. J., Fergusson, D.M., Horwood, L.J. (2008). Gender differences in educational 70 -

Electronic Journal of Research in Educational Psychology, 15(1), 48-74. ISSN: 1696-2095. 2017. no. 41 http://dx.doi.org/10.14204/ejrep.41.16017 
achievement to age 25, Australian Journal of Education, 52(1), 63-80.

doi: https://doi.org/10.1177/000494410805200105

Glówka, D. (2014). The impact of gender on attainment in learning English as a foreign language. Studies in Second Language Learning and Teaching, 4, 617-635. doi: $10.14746 /$ ssllt.2014.4.4.3

Gong, B. (2004). A need for a unified assessment of college English language programs - some theoretical and practical considerations for quality ELT in Taiwan. Shih Chien Management Commentary, Issue 1, 167-182.

Gong, B. (2007). A Critical Study of Evaluation Standards for English Programmes at Soochow University, Taiwan. Paper presented at the 2007 Seminar on Standards for English and Other Foreign Languages in APEC Economies. Ming Chuan University, Taipei, Taiwan.

Granschow, L., Sparks, R., Schneider, E. (1995). Learning a foreign language: Challenges for students with learning difficulties. Dyslexia, 1, 75-95.

Gu, Y. (2002). Gender, academic majors and vocabulary learning strategies of Chinese EFL learners. RELC Journal, 33(1), 35-54. doi: https://doi.org/10.1177/003368820203300102

Hartanto, T. A., Krafft, C. E., Iosif, A. M., \& Schweitzer, J. B. (2015). A trial-by-trial analysis reveals more intense physical activity is associated with better cognitive control performance in attention-deficit/hyperactivity disorder. Child Neuropsychology, 22(5), 618-626. doi: http://dx.doi.org/10.1080/09297049.2015.1044511

Healy, A.F., \& McNamara, D.S. (1997). Verbal learning and memory: Does the modal model still work? Annual Review of Psychology, 47(1), 143-172. doi:10.1146/annurev.psych.47.1.143

Holm, S. (1979). A simple sequentially rejective multiple test procedure. Scandinavian Journal of Statistics, 6(2), 65-70.

Hong-Nam, K., \&Leavell, A.G. (2006). Language learning strategy use of ESL students in an intensive English learning context. System, 34(3), 399-415. http://dx.doi.org/10.1016/j.system.2006.02.002

Javorsky, J. (1996). An Examination of Youth with Attention-Deficit/Hyperactivity 
Disorder and Language Learning Disabilities: A Clinical Study. Journal of Learning Disabilities, 29(3), 247-258.

Jonsdottir, S., Bouma, A., Sergeant, J.A., Scherder, E.J. (2005). The impact of specific language impairment on working memory in children with ADHD combined subtype. Archive of Clinical Neuropsychology, 20(4), 443-56. doi: http://dx.doi.org/10.1016/j.acn.2004.10.004

Kessler, R.C., Alder L., Ames M., Demler O., Faraone S., Hiripi E., Howes M.J., Jin R., Secnik K., Spencer T., Ustun T.B., Walters E.E. (2005). The world health organization adult ADHD self-report scale (ASRS): a short screening scale for use in the general population. Psychological Medicine, 35(2), 245-56. doi: https://doi.org/10.1017/S0033291704002892

Kerr, M., Lambert, W. W., Stattin, H., \& Klackenberg-Larsson, I. (1994). Stability of inhibition in a Swedish longitudinal sample. Child Development, 65(1), 138146.

Lee, J.Y. (2015). Language learner strategy by Chinese-speaking EFL readers when comprehending familiar and unfamiliar texts. Reading in a Foreign Language, 27(1), 71-95.

Martinussen, R., Hayden, J., Hogg-Johnson, S. \& Tannock, R. (2005). A meta-analysis of working memory impairments in children with attention-deficit/hyperactivity disorder. Journal of the American Academy of Child and Adolescent Psychiatry, 44(4), 377-384. doi:10.1097/01.chi.0000153228.72591.73

Oxford, R.L. (1993). Instructional implications of gender differences in L2 learning styles and strategies. Applied Language Learning, 4, 65-94.

Oxford, R.L., Ehrman, M.E. (1995). Adults' language learning strategies in an intensive foreign language program in the United States. System, 23(2), 359-386. doi: http://dx.doi.org/10.1016/0346-251X(95)00023-D

Pan, Y.C. (2013). Does teaching to the test exist? A case study of teacher washback in Taiwan. The Journal of Asia TEFL, 10(4), 185-213.

Park, G.P., French, B.F. (2013). Gender differences in the Foreign Language Classroom Anxiety Scale. System, 41(2), 462-471. doi: http://dx.doi.org/10.1016/j.system.2013.04.001 
Peacock, M., Ho, B. (2003). Student language learning strategies across eight disciplines. International Journal of Applied Linguistics, 13(2), 179-200. doi:10.1111/1473-4192.00043

Polancysk, G., de Lima M., Horta B.L., Biederman J., Rohde L.A. (2007). The worldwide prevalence of ADHD: A systematic review and metaregression analysis. The American Journal of Psychiatry, 164(6), 942-948. doi:10.1176/ajp.2007.164.6.942

Rasmussen, P., Gillberg C. (2000). Natural outcome of ADHD with developmental coordination disorder at age 22 years: A controlled, longitudinal, communitybased study. Journal of American Academy of Child and Adolescent Psychiatry, 39(11), 1424-1431. doi: http://dx.doi.org/10.1097/00004583-200011000-00017

Rucklidge, J. J. (2010). Gender differences in attention-deficit/hyperactivity disorder. Psychiatric Clinics of North America, 33, 357-373. doi: http://dx.doi.org/10.1016/j.psc.2010.01.006

Schatz, D. B., \& Rostain, A. L. (2006). ADHD with comorbid anxiety a review of the current literature. Journal of Attention Disorders, 10(2), 141-149. doi: https://dx.doi.org/10.1177/1087054706286698

Seidman, L. J. (2006). Neuropsychological functioning in people with ADHD across the lifespan. Clinical Psychology Review, 26(4), 466-485.

doi: http://dx.doi.org/10.1016/j.cpr.2006.01.004

Simon, V., Czobor, P., Bálint, S., Mészáros, Á., Bitter, I. (2009). Prevalence and correlates of adult attention-deficit hyperactivity disorder: meta-analysis. British Journal of Psychiatry, 194(3), 204-211. doi: 10.1192/bjp.bp.107.048827

Skogli, E. W., Teicher, M. H., Andersen, P. N., Hovik, K. T., \& Øie, M. (2013). ADHD in girls and boys-gender differences in co-existing symptoms and executive function measures. BMC Psychiatry, 13(1), 298. doi:10.1186/1471-244X-13-298

Sparks, R., Javorsky, J. (1999). Students classified as learning disabled and the foreign language requirement: Replication and comparison studies. Journal of Learning Disablilities, 32(4), 329-349. doi:10.1111/j.1944-9720.1998.tb00598.x

Sparks, R., Philips, L., Ganschow, L., Javorsky, J. (1999). Students classified as learning disabled and the college foreign language requirement: A quantitative 
analysis. Journal of Learning Disabilities, 32(6), 566-580.

Sparks, R., Philips, L., Javorsky, J. (2002). Students classified as LD who received course substitutions for the college foreign language requirement. Journal of Learning Disabilities, 35(6), 482-499, 538. doi: https://doi.org/10.1177/00222194020350060101

Sparks, R. L., Javorsky, J., Philips, L. (2004). College students classified with ADHD and the foreign language requirement. Journal of Learning Disabilities, 37(2), 169-178. doi: https://doi.org/10.1177/00222194040370020701

Sparks, R. L., Javorsky, J., Philips, L. (2005). Comparison of the performance of college students classified as ADHD, LD, and LD/ADHD in foreign language courses. Language Learning, 55(1), 151-177.

doi:10.1111/j.0023-8333.2005.00292.x

Valera, E.M., Brown, A., Biederman, J. (2010). Sex differences in the functional neuroanatomy of working memory in adults with ADHD, American Journal of Psychiatry, 167(1), 86-94.

doi: http://dx.doi.org/10.1176/appi.ajp.2009.09020249

Wang, L.J., Chen, C.K. \& Huang, Y.S. (2015). Gender differences in the behavioural symptoms and neuropsychological performance of patients with attentiondeficit/hyperactivity disorder treated with methylphenidate: A two-year follow-up study, Journal of Child and Adolescent Psychopharmacology, 25(6), 501-508. doi:10.1089/cap.2007.0060.

Winer, B., Brown, D., Michels, K. (1991). Statistical principles in experimental design, Third edition, New York: McGraw-Hill.

Yeh, C. B., Gau, S. S. F., Kessler, R. C., \& Wu, Y. Y. (2008). Psychometric properties of the Chinese version of the adult ADHD Self-report Scale. International Journal of Methods in Psychiatric Research, 17(1), 45-54.

doi: https://dx.doi.org/10.1002/mpr.241 